\title{
Quality Assurance of Medical Education in China: Demand and Measures \\ Jing $\mathrm{Ma}^{*}$
}

Clinical College of Guilin Medical University, Guilin 541001, China

DOI: $10.36347 /$ sjams.2020.v08i05.022

| Received: 30.04.2020 | Accepted: 13.05.2020 | Published: 16.05.2020

*Corresponding author: Jing Ma

Abstract

With the development of society, medicine and medical environment have changed in China. People pay more and more attention to life and health. They strongly expect to train excellent doctors with high quality, strong ability. Good health is a basic public necessity, so we must work consistently to raise the standard of medical and healthcare services to accelerate "Healthy China". The importance of medical education is more prominent. Quality is the "lifeline" of medical education and the core to improve the cultivation of Medical Talents. It is of great significance to strengthen the construction of quality guarantee for medical education to cultivate a large number of qualified medical personnel.

Keywords: Medical education quality assurance China.

Copyright @ 2020: This is an open-access article distributed under the terms of the Creative Commons Attribution license which permits unrestricted use, distribution, and reproduction in any medium for non-commercial use (NonCommercial, or CC-BY-NC) provided the original author and source are credited.

\section{INTRODUCTION}

Now, China is implementing "Healthy China Initiative". It is an inevitable requirement for building a healthy China to cooperation medical education, promote the reform and development of medical education, accelerate the training of a large number of qualified medical talents, and provide better medical services for people. Ministry of Education and other six departments issued "Opinions on Deepening the Reform of Clinical Medical Personnel Training in Cooperation with Medical Education" in June, 2014. The State issued" Opinions on Deepening the Coordination to Promote the Reform and Development of Medical Education" in July, 2017, which pointed out that medical education and personnel training should always be given priority in the strategic position. In October, President Xi put forward to carry out "Healthy China initiative".

This is not an easy task. It is a strategic layout in the critical period of medical reform with many difficulties. Furthermore, medicine is undergoing profound changes on the world in recent years. The new trend of medical development poses new challenges to medical education in China. It has become an important task to coordinate medical education, improve the quality of medical education, train a large number of first-class medical talents, and serve the construction of a healthy China [1]. Quality is the lifeline of medical education, and the current core is to improve the quality of medical personnel training. Therefore, we need to strengthen medical quality assurance [2].

Higher education quality assurance rose in Europe in the 1980s.It started relatively late in China. At the end of the 20th century, Chinese government made a major decision to speed up higher education. In 1985, the Ministry of Education started the pilot work of evaluation of the level, specialty and curriculum of higher education, and ensured the quality of higher education by evaluation. It became the policy choice of the state and the direction of the reform of higher education management system in China [3]. In August, 2004, the higher education teaching evaluation center formally was established, belonging to Ministry of Education. This marked a critical step in establishing a higher education quality assurance system with Chinese characteristics [4].

Medical education involves education and medical treatment. They are two the most critical issues about livelihood. The purpose of medical education is to train qualified medical talents and meet the health needs of people [5]. The development of health undertaking not only provides better conditions and environment for the training of medical talents, but also attracts more excellent talents to study and practice medicine, and puts forward new requirements for the reform of medical education. 
We should take quality as the lifeline of medical education that is the key to realize the organic integration of improving quality and quality assurance [6]. Then, by the study, to construct a mature and complete quality assurance system, we should take the following measures in medical colleges and universities.

\section{Internal quality assurance}

Currently in China, colleges and universities occupy an important position in the quality assurance of higher education. After the transition of economic system, the government quickly withdrew from micromanagement, and colleges and universities began to truly face the market and run their own schools [7]. If the quality is not satisfied, the talents cultivated by the school cannot meet the needs of the society and play their due role, the school will be eliminated in the face of fierce market competition. Therefore, colleges and universities are internal main body of quality assurance.

Firstly, we need to strengthen coordination and build quality assurance institutions, which aim to ensure that the quality management work is organized, the responsibility is in place, and the operation is efficient [8]. All units, including teaching units and functional departments, related to each teaching link in medical colleges and universities. They are the main body of teaching quality management. So, quality assurance institutions should be a reasonable structure with clear rights and responsibilities, which are jointly participated in by all stakeholders, through consultation and information sharing [9].

In general, quality assurance institution should have a decision-making consulting system, an execution system and an evaluation system .The decision-making consultation system is composed of the standing committee of the university party committee, the president's office, the academic committee, and the teaching work committee. The academic committee and the teaching work committee make suggestions on the major issues of the teaching work. The implementation system is composed of the academic affairs office and each teaching unit [10]. The academic affairs office is responsible for directing and coordinating the activities of the school's education quality management, coordinating the undergraduate teaching management of the university, summarizing the quality assurance experience, collecting and feedback the teaching process information, and dealing with major teaching events. Each teaching unit is responsible for the specific organization and implementation of each professional talent training process.

Secondly, we should set up the teaching quality monitoring and supervision system. System in place, effective monitoring. The supervision system of teaching quality is the supervision mechanism of teachers' teaching and students' learning. From the perspective of diversity and science, we monitor the quality of personnel training [11]. To ensure the standard operation of the whole teaching process, We establish unblocked information feedback network to monitor all the way through internal factors (teachers, students, management, etc.) and the external factors (guidelines, policies , system, etc.), the scientific evaluation and analysis.

Quality control is carried out by binding organizations in colleges and universities, such as academic committee, teaching committee and teaching supervision group, etc. which play an important role in the quality control of the school. The supervision system is established and perfected according to permission to supervisor of the institution structure and management. The professional teaching supervisors monitor teachers' teaching, students' learning situation, then give clear and effective oppions on teaching and learning so as to inprove monitoring results[12].

At last, we should inprove the evaluation system of quality assurance. Evaluation system is composed of teaching supervision team, teaching quality control center, and employer. These departments are responsible for teaching information collection feedback, regular and special teaching inspection. Teaching evaluation usually includes leaders' evaluation, experts' evaluation, students' evaluation and colleague evaluation.[13]Hence, the comprehensive evaluation results are dominated by other evaluation. But teachers' self-evaluation was ignored. Only by adding self-evaluation can teachers get comprehensive and objective evaluation of their own education and teaching quality.

After the construction of the evaluation system, it is necessary to make a comprehensive analysis of the results of various teaching evaluation, and make an assessment of the authenticity of the diversified evaluation indexes, so as to ensure the objective rationality of the quality of personnel training and make a scientific and objective evaluation of the teaching quality of teachers. Complete evaluation, feedback adjustment and incentive oriented policies [14]. We should strengthen the construction of quality assessment centers, establish quality assessment standards for talent training and constantly improve the quality assurance system guided by results. Establish the teaching quality evaluation and monitoring system, optimize the quality standards of each teaching link, adjust the quality operation mechanism of daily sustainable improvement, and explore the separation mechanism of teaching, management and evaluation[15].

\section{External quality assurance}

The external subject of supervision is also a powerful lever for quality assurance of medical education. Social forces are becoming stronger and 
more involved in higher education. As the final demand body of public goods and services, higher education not only produces the supply body of higher education, but also plays an increasingly important role in the quality management .With the further reform in China, colleges and universities have become independent legal entities and school-running subjects, so the government, society and universities have become three main bodies to monitor quality. In 2011, the national association of quality assurance and evaluation institutions of higher education was established. As a social organization, it is guided by the association of higher education, committed to the organizational construction and capacity improvement of national institutions of quality assurance and evaluation of higher education,. It actively played the role of social organizations in the public governance of education. So far, there have been 12 independent provincial educational evaluation institutions and over 300 school evaluation and construction institutions [16].

As social third-party evaluation, it attaches great importance to the evaluation of employers' demand degree, students' adaptability and satisfaction degree, and the feedback rectification and optimization plan of professional education institutions for the evaluation of graduates. The evaluation and appraisal system of learning outcomes plays an important guiding role, which is not only meaningful for stimulating learners' learning enthusiasm, but also helpful for learners to make convenient and effective connection between different types and levels of learning. It is very important to improve the quality. Based on the "studentcentered study", this paper conducts a survey on the satisfaction of graduates, employers and interns, and timely feedbacks the survey results to each teaching unit, so as to provide a reference basis for the revision of the professional talent cultivation program and the teaching design, so as to establish a closed loop of teaching evaluation feedback application.

The graduation practice is usually carried out in the teaching hospital, which is regarded as the external evaluation. Clinical practice during medical education is an essential way to train clinical skills and effective means of teaching in which theories are applied to practice. Teaching hospitals are hospitals where new doctors, known as residents come for more training after medical school. The quality control of graduation practice is carried out in the three-level system of school, college and hospital, with clear division of labor and responsibility. In the general management mode of graduation practice, the teaching quality center conducts overall supervision of graduation practice under the leadership of the vice President in charge of teaching. The supervision team of the clinical college is responsible for supervising the specific organization and management of the graduation internship. Under the organization of the quality center, it is necessary to supervise the specific implementation of graduation practice in the teaching hospital [17]. To perfect and strengthen the evaluation requirements of teaching work in affiliated hospitals of colleges and universities; We should improve the ability-oriented evaluation system, strictly manage the clinical practice and training, strengthen the teaching of clinical practice, and improve the clinical thinking and practice ability of medical students.

\section{Professional Certification of Clinical Medicine}

As an external quality assessment mechanism, medical education certification is to review and evaluate medical schools or educational programs according to standards and procedures used by certification bodies. It's aim is to judge whether medical colleges or education project meet quality standards, to encourage medical colleges to improve the quality of education[18] .

World Federation for Medical Education (WFME) established the "International Standard of Medical Education" project in 1998. WFME released "The Undergraduate Medical Education Standards in the world" in July, 2001.Chinese Medicine Foundation (CMB) then formulated "the Global Minimum Essential Requirements (GMER)".In 2012, a new revision of the standards of the world federation of medical education was fininshed. Professional certification in China dates back to the beginning of this century. Since 2002, China has been conducting research and building its own national accreditation system for medical education. In May 2006, Harbin Medical University became the first school in China to conduct pilot certification based on WFME global standard for undergraduate medical education. In 2008, Ministry of Education and the former Ministry of Health jointly issued "Undergraduate Medical Education Standard -- Clinical Medical Specialty (trial)".Clinical medicine professional certification system established in China. In 2011, Higher Education Teaching Evaluation Center of Ministry of Education organized and implemented 180 pilot programs of undergraduate professional certification. In 2012, the key points of work again proposed to explore and establish relevant professional certification standards. Meanwhile, the new standards of the world federation of medical education was revised, which gave pressure and impetus to domestic medical educators to keep up with the international pace.

After several years of efforts and revisions, the "Chinese Undergraduate Medical Education Standards - Clinical Medical Specialty (2016 edition)" and "Undergraduate Clinical Medical Specialty Certification Guidelines (2016 edition)" were completed at the end of 2016.

According to the certification standards accepted by the word, the certification working committee has formed the certification process of 
"certification application -- school self-evaluation -- onsite inspection -- certification feedback and certification report -- continuous improvement" [19]. In combination with the actual situation of medical education in China, the Chinese model of preliminary inspection system and return visit system is established, which embodies the principles of "promoting construction by evaluation" and "continuous improvement".

In fact, the sooner a medical school is accredited, the sooner it will benefit. By the end of 2017, 73 medical colleges had accepted clinical medicine professional certification, which accounts for about $47.7 \%$ of the total number of undergraduate institutions of clinical medicine in China.

In virtue of it, we timely discover and solve the problems and defects existing in the current medical colleges. Most importantly, the first educational standards and guidelines in the history of modern medical education in China, "Guidelines for standards and accreditation of undergraduate medical education in China" was formulated and promulgated, and "the Chinese undergraduate medical education standards -clinical medical specialty (2016)" was revised and released.

The 2016 version reflects the international trend, domestic status and social expectation of medical education, and provides the basis and guidance for clinical medical education, and is in line with international standards.Focusing on continuous improvement instead of prioritizing is a principle that has been emphasized throughout the certification process.

In 2018, Mministry of Education decided to establish a new clinical medicine professional certification committee. The committee would undertake to establish and perfect clinical medicine professional certification, carry out clinical medicine professional certification work and so on[20].

From the start to now, Chinese clinical medicine professional certification always gets the continued guidance and support of relevant state departments. The project is making steady progress towards the goal to form a high level of medical education with Chinese characteristics and international essence equivalent certification system, to make contributions to the world medical education standards with Chinese wisdom, Chinese plan.

\section{Conclusion}

It is an arduous system task to improve medical education quality. Quality assurance is now facing some difficulties in China. We should have a clear picture about it. To make a comprehensive and effective push in the field, we should not only rely on schools, secondary colleges, teaching hospitals to jointly perform quality assurance but also accelerate professional certification system of a medical education with Chinese characteristics.

\section{REFERENCES}

1. Niu JX, Wei wi, Zhang T. Requirements and implementation effects of professional certification on teaching quality control, Henan education (higher education). 2018(10): 40-42.

2. Cao J, Tang ZQ, WangDH. Construction of teaching quality control system in secondary colleges of local universities, Modern education science. 2017(6): 69-73.

3. Zhu YH, Zhou J. Research on teaching quality assurance system of second-level colleges in universities -- from the perspective of undergraduate teaching audit and evaluation. Modern vocational education, 2018 (11) : 20-23.

4. Wei Y. New review and evaluation of undergraduate teaching work. Hunan social science, 2017 (9): 174-180.

5. Wang HX, Zhang Y, Liang ZSH. Research on innovative talent cultivation mechanism in universities under the background of "double firstclass" construction. Curriculum education research. 2019 (1): 29-30.

6. Lin DH. Review and evaluation: development context, current situation analysis and future prospect -- based on the research of 51 participating universities. Modern education science, 2016 (9): 1-7.

7. Zhang dejiang. Teaching quality assurance system construction from the perspective of teaching work evaluation]. China higher education. 2014 (3): 3436.

8. Liu huadong, Lli ZHJ, Chen qiang. Improvement and reconstruction of college teaching quality assurance system from the perspective of auditing and evaluation. China university teaching. 2017(11): 63-67.

9. Wu Yan. The new situation of higher education in the new era]. Guangming daily, 2017-12-19 (13).

10. Liu changxu. Grasping the new era and new mission to effectively promote the connote development of higher education. Beijing education (higher education). 2017 (12): 11.

11. Liu kun, Li JH. The evolution and deepening strategies of the essential connotation of innovation and entrepreneurship education.Heilongjiang higher education research, 2016 (1) : 117-120.

12. Liu zhentian.Transformation and development of local undergraduate institutions and higher education cognition and methodology.China higher education research. 2014 (6): 11-17.

13. You xiaoling, Ma YK, Ma L.The reform and practice of practice teaching evaluation systeme.China electric power education. 2013(22): $172-173+183$.

14. $\mathrm{Yu}$ menghui.On the transformation of local colleges and universities and the quality standard of 
talent cultivation.Education and careers. 2015(3): 27-29.

15. Li xiaoguang. Practice research on teaching quality monitoring and guarantee system based on application-oriented talent cultivation .Teaching and educating (higher education forum), 2018(9) : 36-37.

16. Yi Wei. Review and evaluation of undergraduate teaching, Hunan social sciences. 2017 (05).

17. Qingzhong Chang. Four changes of audit and evaluation and internal quality assurance system construction in universities, Teaching in Chinese universities. 2013 (07).
18. Zhenchuan Zhang, Quanfeng, research on continuing education and its quality assurance from the perspective of TQM, Shi. Education and teaching forum. 2018 (33).

19. Donghua Lin. review and evaluation: development context, status analysis and future outlook -- based on the research of 51 participating universities, Science of modern education. 2016 (09).

20. Liu qiang. on the reconstruction of the value concept and behavior model of the teaching quality assurance system in Chinese universities, Jiangsu higher education. 2018 (02). 